\title{
Comparison of Health Care Expenditure Patterns between Various Income Deciles: Iran Urban Households (2009-2014)
}

\author{
Dr.Abbas Assari Arani \\ Assistance professor, Tarbaiat Modares University \\ Email: assari_a@modares.ac.ir \\ Hessam Mardantabar \\ PHD student, Tarbaiat Modares University \\ Email: h.mardantabar@gmail.com \\ Dr. Loft Ali Agheli \\ Assistance Professor, Tarbaiat Modares University

\section{Dr. Ghahreman Abdoli}

Associate Professor, Tehran Uinversity

Doi:10.5901/mjss.2017.v8n2p301

\section{Abstract}

This study estimates and compares healthcare expenditure patterns of different income deciles of urban households by ordinary least square (OLS) method. Data is obtained from houshold survey data and includes healthcare expenditure, family income, the education level of parents, number of children and the average age of parents during 2009-2014. The purpose is to identify the effectiveness of each variable on healthcare expenditure between different income deciles. Moreover, it will be examined that if there is any significant difference between effects of variables on healthcare expenditure in different income deciles. The results indicate that the pattern of healthcare expenditure varies between different income deciles. The first and second deciles show a similar pattern and the level of education of parents doesn't have any significant effect on the healthcare expenditure. In these deciles, a percent increase in family income, increases the healthcare expenditure less than 1 percent. In addition, other variables except than the education level have a positive effect on the healthcare expenditure. On the other hand, almost the same pattern is observed in other income deciles as well. Thus, family income, the average age of parents and number of children demonstrated a positive effect on healthcare expenditure and the education level of parents showed a negative effect. This finding seems to be related to the preventive effects of education. What's more is that in the ninth and tenth deciles, a percent increase in family income, leads to more than 1 percent increase in healthcare expenditure. Therefore, the most prominent suggestion to healthcare authorities is to improve the level of awareness of family. And also, this instruction can be categorize base on the average age of parents. This could be done through government agencies or insurance authorities.

\section{Introduction}

Healthcare expenditure is one of the most important indices in health economics. Therefore, analyzing the behavior of household's healthcare expenditure is very useful for policymakers and economists. This paper tries to recognize whether the behavior of urban households in different income deciles is similar or not. There are two distinct approaches to do so: macroeconomic data and household survey data. Most of previous studies used macroeconomic data to develop a comprehensive set of determinants of healthcare expenditure. Household survey database is used less frequently due to the complexities with this method. For example, high volume of data (around 19000 observations every year) makes the classification more difficult in comparison with the others. However, the data is micro-founded and reach. So, this paper chooses the household survey data approach to make use of all available data.

The most famous and influential paper in health economics is Grossman (1972) which provides the basic theoretical model for demand of health. According to the theories, a strong relationship between demand for health and healthcare expenditure is expected. This reflects the fact that spending money on healthcare improves the health status. 
Therefore, it is anticipated that variables affecting health status to be common with the healthcare expenditure determinants. Grossman's model indicates that age, education and income levels are the most important variables for explaining individual behavior toward health and healthcare expenditure. The other old source is Newhouse's paper (1977) which explores that if healthcare expenditure is a luxury good. This research has detected income elasticity to be above unity, implying that the share of health expenditure of GDP increases with the rise in per capita income. However, other papers like Smith, Newhouse, and Freeland (2009) and Follette and Sheiner (2008 and 2014), declare that household-level estimates may not be predicted and illustrated by macroeconomic data. Therefore, they propose that adopting microeconomic data is more useful for estimating income elasticity. For example, Getzen 2000 has compared health consumption of different income levels by using household survey data at a single point in time. Similarly, Amy Finkelstein (2007 and 2015) showed that analyzing the effect of medical service prices is not accurate without considering the role of insurance. Dalgaard and Strulik $(2012,2014,2015)$ have investigated the role of age in healthcare expenditure and find it to be one of the most important effecting variables of healthcare expenditure. Wagstaff's (1986) effort for identifying effecting variables of demand for health and healthcare expenditure finds family income, age of family and family size as the most important variables to consider. Gerdtham (1997) has used Sweden micro data and showed that income, age and education are the most effective variables. F. A. Gregersen (2014) has investigated the effects of aging on healthcare expenditure and finds it as the central variable.

Barati ,Ghaderi and Deily (2006) have investigated average healthcare expenditure of different income classes in Kerman province (IRAN) from 1996 to 2002. The results show that average healthcare expenditure of low income households is significantly different from middle and high income households in urban areas. It also shows that rural area expenditures are different from urban areas. However, even there average expenditure differs among different income classes. Ardalan and Rasael (2007) have focused on aging and the rapid growth of elderly to indicate future healthcare expenditure prospects. They reviewed aging population statistics in several courtiers, as well as Iran, and illustrated the significance of the aging population growth in the decades to come. They report a noteworthy difference on healthcare expenditure for less than 65 years and over 65 years. Finally, the importance of aging population and future healthcare expenditure studies is concluded.

\section{Methodology}

In this study, household survey data of Iran from 2009 to 2014 is used. This data comes from statistical center of Iran. However, the most distinct aspect of this paper is categorizing the variables based on the income deciles, which is done by Microsoft Access. Estimates are made via STATA software. According to the above literature, the most comprehensive set of effecting variables of healthcare expenditure is considered. The variables include family income, average of age of father and mother, education level of father, education level of mother and number of children. Due to the structure of the data and the nature of research question, ordinary least square ${ }^{1}(\mathrm{OLS})$ is the most appropriate method to be used. So, first of all, we have tested that whether behavior of households during 2009 to 2014 is similar among various income deciles or not? Then, since we concluded that there is such a difference, we have estimated healthcare expenditure function at different income deciles. This means that First of all, we have examined the behavior of households during 2009 to 2014 to see whether it is similar among various income deciles or not? Then, after verifying the difference, we have estimated healthcare expenditure function at different income deciles. The estimated equation is:

The estimated equation is:

lnexpenditure $=\alpha_{0}+\alpha_{1} *$ lnincome $+\alpha_{2} * N$ children $+\alpha_{3} *$ Age $+\alpha_{4} *$ education_ $f+\alpha_{5} *$ education_m

In which,

Lnexpenditure represents the logarithm of healthcare expenditure of family,

Lnincome represents the logarithm of family income,

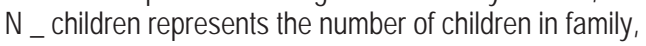

education _ $f$ represents the level of education of father,

education _ $m$ represents the level of education of mother

and Age represents the average age of father and mother.

Equation (1) is estimated in different income deciles each year. As a result, it would be probable to identify effecting variables of healthcare expenditure in different income deciles each year for the duration of 6 years. Therefore, the central question of this research about household's behavior among income deciles will be answered and policy implication could be suggested to policymakers and insurance authorities.

1 OLS 


\section{Results and Discussion}

As stated above, first we tested that if there is a significant difference between various income deciles on effecting variables of healthcare expenditure during 2009 to 2014. As table (1) shows, different income deciles have significant effects on the extent of effectiveness of variables.

Table (1): Effecting variables of healthcare expenditure in various income deciles

\begin{tabular}{|c|c|c|c|c|}
\hline Indaraman & Coef. & Std. Err. & $\mathrm{t}$ & $\mathrm{P}>\mathrm{t}$ \\
\hline Inincome & 0.932 & 0.008 & 117.38 & 0.00 \\
\hline education-f & 0.000 & 0.000 & -13.69 & 0.02 \\
\hline education_m & 0.000 & 0.000 & -12.32 & 0.01 \\
\hline N_children & 0.082 & 0.003 & -28.83 & 0.03 \\
\hline AGE & 0.007 & 0.000 & 26.18 & 0.04 \\
\hline Decile & 0.007 & 0.002 & 3.68 & 0.023 \\
\hline cons & -2.228 & 0.114 & -19.6 & 0.014 \\
\hline
\end{tabular}

Average healthcare expenditure of various income deciles in every month in depicted in Figure (1). As graph shows, it is evident that the pattern of healthcare expenditure differs considerably among different income deciles. On the other hand, although healthcare expenditure has evolved during time, the overall pattern is similar.

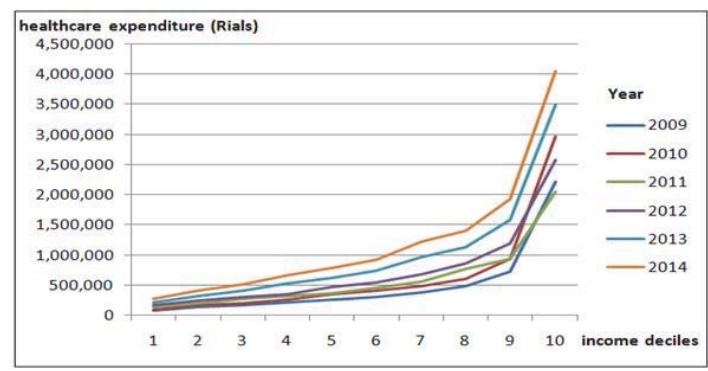

Figure (1): Average healthcare expenditure of various income deciles: 2009-2014

Considering above results, it is obvious that the pattern of healthcare expenditure during these 6 years regarding income deciles is approximately similar. Therefore, we can go one step forward and estimate effecting variables of healthcare expenditure in different income deciles during 2009 to 2014. After various estimations and performing post estimation tests, we concluded that the best categorization of income deciles in to consider every two consecutive deciles as a group. So, we have divided the data to five different groups; each consecutive two deciles. The results are presented in tables (2) and table (3).

Table (2): Effecting variables of healthcare expenditure in various income deciles: 2009- 2011

\begin{tabular}{|c|c|c|c|c|c|c|c|}
\hline year & Income deciles & Results/ Variables & Inincome & N_children & Age & education_f & education_m \\
\hline \multirow{10}{*}{2009} & \multirow{2}{*}{ First and second } & Coef. & 0.792 & 0.057 & 0.005 & * & * \\
\hline & & $\mathrm{P}>\mathrm{t}$ & 0.000 & 0.001 & 0.000 & * & * \\
\hline & \multirow{2}{*}{ Third and fourth } & Coef. & 0.850 & 0.083 & 0.006 & -0.001 & -0.001 \\
\hline & & $\mathrm{P}>\mathrm{t}$ & 0.000 & 0.003 & 0.094 & 0.002 & 0.017 \\
\hline & \multirow{2}{*}{ Fifth and sixth } & Coef. & 0.897 & 0.092 & 0.007 & -0.002 & -0.001 \\
\hline & & $\mathrm{P}>\mathrm{t}$ & 0.000 & 0.003 & 0.004 & 0.044 & 0.006 \\
\hline & \multirow{2}{*}{ Seventh and eighth } & Coef. & 0.952 & 0.110 & 0.007 & -0.003 & -0.002 \\
\hline & & $\mathrm{P}>\mathrm{t}$ & 0.000 & 0.085 & 0.018 & 0.000 & 0.056 \\
\hline & \multirow{2}{*}{ Ninth and tens } & Coef. & 1.150 & 0.122 & 0.008 & -0.004 & -0.002 \\
\hline & & $P>t$ & 0.000 & 0.000 & 0.001 & 0.000 & 0.063 \\
\hline
\end{tabular}




\begin{tabular}{|c|c|c|c|c|c|c|c|}
\hline year & Income deciles & Results/ Variables & Inincome & N_children & Age & education_f & education_m \\
\hline \multirow{10}{*}{2010} & \multirow{2}{*}{ First and second } & Coef. & 0.764 & 0.163 & 0.006 & * & * \\
\hline & & $\mathrm{P}>\mathrm{t}$ & 0.000 & 0.005 & 0.000 & * & * \\
\hline & \multirow{2}{*}{ Third and fourth } & Coef. & 0.801 & 0.292 & 0.006 & -0.003 & -0.003 \\
\hline & & $\mathrm{P}>\mathrm{t}$ & 0.000 & 0.012 & 0.000 & 0.020 & 0.018 \\
\hline & \multirow{2}{*}{ Fifth and sixth } & Coef. & 0.857 & 0.319 & 0.007 & -0.003 & -0.003 \\
\hline & & $\mathrm{P}>\mathrm{t}$ & 0.000 & 0.049 & 0.000 & 0.004 & 0.000 \\
\hline & \multirow{2}{*}{ Seventh and eighth } & Coef. & 0.918 & 0.483 & 0.010 & -0.004 & -0.004 \\
\hline & & $\mathrm{P}>\mathrm{t}$ & 0.000 & 0.021 & 0.000 & 0.035 & 0.006 \\
\hline & \multirow{2}{*}{ Ninth and tens } & Coef. & 1.165 & 0.891 & 0.013 & -0.005 & -0.004 \\
\hline & & $\mathrm{P}>\mathrm{t}$ & 0.000 & 0.004 & 0.000 & 0.005 & 0.033 \\
\hline \multirow{10}{*}{2011} & \multirow{2}{*}{ First and second } & Coef. & 0.764 & 0.351 & 0.006 & * & * \\
\hline & & $\mathrm{P}>\mathrm{t}$ & 0.000 & 0.007 & 0.000 & * & * \\
\hline & \multirow{2}{*}{ Third and fourth } & Coef. & 0.715 & 0.416 & 0.008 & -0.006 & -0.005 \\
\hline & & $\mathrm{P}>\mathrm{t}$ & 0.000 & 0.062 & 0.000 & 0.026 & 0.028 \\
\hline & \multirow{2}{*}{ Fifth and sixth } & Coef. & 0.898 & 0.536 & 0.010 & -0.008 & -0.006 \\
\hline & & $\mathrm{P}>\mathrm{t}$ & 0.000 & 0.009 & 0.000 & 0.007 & 0.032 \\
\hline & \multirow{2}{*}{ Seventh and eighth } & Coef. & 1.011 & 0.634 & 0.012 & -0.008 & -0.007 \\
\hline & & $\mathrm{P}>\mathrm{t}$ & 0.000 & 0.040 & 0.000 & 0.004 & 0.034 \\
\hline & \multirow{2}{*}{ Ninth and tens } & Coef. & 1.191 & 0.725 & 0.016 & -0.009 & -0.008 \\
\hline & & $\mathrm{P}>\mathrm{t}$ & 0.000 & 0.003 & 0.000 & 0.005 & 0.032 \\
\hline
\end{tabular}

The results show that effecting variables of healthcare expenditure in the first and second income deciles are family income, average of age father and mother and the number of children respectively. This implies that the education levels of parents are not important in these income deciles. Moreover, all variables have a positive effect on healthcare expenditure; which means that an increase in family income, average of age father and mother and number of children increases healthcare expenditure of these income deciles in the research period. Because of the logarithmic nature of family income and healthcare expenditure, coefficient of Inincome shows that in these deciles a percent increase in the family income, leads to less than 1 percent increase in healthcare expenditure during 2009 to 2011 . In other income deciles, effecting variables of healthcare expenditure are family income, average of age father and mother and the number of children and the education level of parents respectively. The results demonstrate that while family income, average of age father and mother and number of children have positive effects on healthcare expenditure, the education level of parents has a negative effect. This can be related to the Preventive effect of education; which indicates that when the level of education of parents increases, they are able to manage the health level of family more effectively. Therefore, healthcare expenditure could be expected to be decreased. The other noteworthy result is that effects of all variables on healthcare expenditure increases by moving upward in income deciles. This illustrates that we are facing an increasing trend of the absolute value of coefficients for every variable in each year. Thus, effectiveness of variables on healthcare expenditure increases by upward moving in income deciles. In this regard, in the Ninth and tenth income deciles healthcare expenditure could be considered as a luxury good to the household.

Table (3): Effecting variables of healthcare expenditure in various income deciles: 2012-2014

\begin{tabular}{|c|c|c|c|c|c|c|c|}
\hline year & Income deciles & Results/Variables & Inincome & child.N & Age & Head.GRA & Wife.GRA \\
\hline \multirow{10}{*}{2012} & \multirow{2}{*}{ First and second } & Coef. & 0.701 & 0.069 & 0.005 & * & * \\
\hline & & $\mathrm{P}>\mathrm{t}$ & 0.000 & 0.001 & 0.001 & * & * \\
\hline & \multirow{2}{*}{ Third and fourth } & Coef. & 0.818 & 0.076 & 0.004 & -0.001 & -0.001 \\
\hline & & $\mathrm{P}>\mathrm{t}$ & 0.000 & 0.047 & 0.027 & 0.010 & 0.010 \\
\hline & \multirow{2}{*}{ Fifth and sixth } & Coef. & 1.059 & 0.086 & 0.008 & -0.002 & -0.002 \\
\hline & & $\mathrm{P}>\mathrm{t}$ & 0.000 & 0.025 & 0.000 & 0.025 & 0.025 \\
\hline & \multirow{2}{*}{ Seventh and eighth } & Coef. & 1.096 & 0.128 & 0.008 & -0.002 & -0.002 \\
\hline & & $\mathrm{P}>\mathrm{t}$ & 0.000 & 0.002 & 0.000 & 0.028 & 0.028 \\
\hline & \multirow{2}{*}{ Ninth and tens } & Coef. & 1.195 & 0.144 & 0.015 & -0.003 & -0.003 \\
\hline & & $\mathrm{P}>\mathrm{t}$ & 0.000 & 0.001 & 0.000 & 0.032 & 0.032 \\
\hline
\end{tabular}




\begin{tabular}{|c|c|c|c|c|c|c|c|}
\hline year & Income deciles & Results/Variables & Inincome & child.N & Age & Head.GRA & Wife.GRA \\
\hline \multirow{10}{*}{2013} & \multirow{2}{*}{ First and second } & Coef. & 0.616 & 0.064 & 0.004 & * & * \\
\hline & & $\mathrm{P}>\mathrm{t}$ & 0.000 & 0.003 & 0.004 & * & * \\
\hline & \multirow{2}{*}{ Third and fourth } & Coef. & 0.912 & 0.087 & 0.006 & -0.003 & -0.003 \\
\hline & & $\mathrm{P}>\mathrm{t}$ & 0.000 & 0.009 & 0.000 & 0.019 & 0.019 \\
\hline & \multirow{2}{*}{ Fifth and sixth } & Coef. & 1.059 & 0.088 & 0.006 & -0.003 & -0.003 \\
\hline & & $\mathrm{P}>\mathrm{t}$ & 0.000 & 0.022 & 0.000 & 0.002 & 0.002 \\
\hline & \multirow{2}{*}{ Seventh and eighth } & Coef. & 1.088 & 0.099 & 0.008 & -0.004 & -0.004 \\
\hline & & $\mathrm{P}>\mathrm{t}$ & 0.000 & 0.019 & 0.000 & 0.020 & 0.020 \\
\hline & \multirow{2}{*}{ Ninth and tens } & Coef. & 1.086 & 0.100 & 0.011 & -0.005 & -0.005 \\
\hline & & $\mathrm{P}>\mathrm{t}$ & 0.000 & 0.001 & 0.000 & 0.019 & 0.019 \\
\hline \multirow{10}{*}{2014} & \multirow{2}{*}{ First and second } & Coef. & 0.781 & 0.077 & 0.005 & * & * \\
\hline & & $\mathrm{P}>\mathrm{t}$ & 0.004 & 0.000 & 0.001 & * & * \\
\hline & \multirow{2}{*}{ Third and fourth } & Coef. & 0.967 & 0.084 & 0.005 & -0.005 & -0.005 \\
\hline & & $\mathrm{P}>\mathrm{t}$ & 0.031 & 0.002 & 0.060 & 0.027 & 0.027 \\
\hline & \multirow{2}{*}{ Fifth and sixth } & Coef. & 1.017 & 0.096 & 0.008 & -0.007 & -0.007 \\
\hline & & $\mathrm{P}>\mathrm{t}$ & 0.005 & 0.000 & 0.002 & 0.019 & 0.019 \\
\hline & \multirow{2}{*}{ Seventh and eighth } & Coef. & 1.230 & 0.112 & 0.008 & -0.008 & -0.008 \\
\hline & & $\mathrm{P}>\mathrm{t}$ & 0.020 & 0.001 & 0.009 & 0.019 & 0.080 \\
\hline & \multirow{2}{*}{ Ninth and tens } & Coef. & 1.280 & 0.124 & 0.011 & -0.008 & -0.012 \\
\hline & & $\mathrm{P}>\mathrm{t}$ & 0.002 & 0.000 & 0.001 & 0.019 & 0.041 \\
\hline
\end{tabular}

The results show the same behavior for the households in the first and second income deciles as period 2009 to 2011. The education level of parents is not important in these income deciles in the period 2012 to 2014 as well. Moreover, all of these variables have positive effects on healthcare expenditure; which means that increase of family income, average of age father and mother and the number of children increases the healthcare expenditure of these income deciles during research period. Here again the effect of income increase on healthcare expenditure is the same as the previous period. This means that if family income is increased 1 percent, healthcare expenditure would be increased less than 1 percent. Similarly, effecting variables of healthcare expenditure in the other income deciles are family income, average of age father, mother and the number of children and the education level of parents. According to the results, family income, average of age of father and mother and number of children have positive effects on healthcare expenditure, but the education level of parents has a negative effect. This can be related to the Preventive effect of education; which indicates that when the level of education of parents increases, they are able to mange the health level of family more effectively. The other important result is that effects of all variables on healthcare expenditure increases by increasing income deciles. This illustrates that we are facing an increasing trend of the absolute value of coefficients for every variable in each year. Thus, effectiveness of variables on healthcare expenditure increases by upward moving in income deciles. In this regard, the Ninth and tenth income deciles healthcare expenditure could be considered as a luxury good to the household.

\section{Conclusion}

This paper has analyzed household behavior of various income deciles regarding healthcare expenditure during 2009 to 2014 in Iran. This is done through identifying effective variables of healthcare expenditure. The results indicate that the behavior of the first and second income deciles is similar and the education level of parents doesn't have any significant effect on healthcare expenditure. Moreover, in these income deciles if family income is increased by 1 percent, healthcare expenditure would increase less than 1 percent. Furthermore, in these income deciles, other variables have positive effects on healthcare expenditure. The other important result is that we are facing a similar pattern in other deciles. Therefore, family income, average of age of father and mother and the number of children all have positive effects on healthcare expenditure. On the other hand, the education level of parents negatively affects the healthcare expenditure; which could be related to the Preventive effect of education. However, in ninth and tenth deciles, if family income is increased by 1 percent, healthcare expenditure would be increased more than 1 percent. Therefore the, most important suggestion for managing healthcare expenditure is to improve the level of awareness of family. The same instruction could be to categorize base on the average age of parents. This program can be done by government agencies and insurance authorities. Therefore, healthcare authorities are highly suggested to thrive to lift up the awareness level of family. 


\section{Reference}

Barati Marnani, A., Qaderi, H . Haj Hassani Daily. (2006). Study consumption patterns of health services in the consumption basket of households Kerman province in 1997-2002. Monitoring Journal. Spring. Vol.5, No.2, 105 - 111.

Dalgaard, C-J., Strulik, H. (2012). The genesis of the golden age: Accounting for the rise in health and leisure. Working Paper, University of Copenhagen.

Dalgaard, C-J., Strulik, H. (2014). Optimal aging and death: Understanding the Preston Curve. Journal of the European Economic Association. Volume 12, 672-701.

Dalgaard, C-J., Strulik, H. (2015).The Economics of Health Demand and Human Aging: Health Capital vs. Health Deficits .journal of political economy. Volume 30, 40-72

Finkelstein, Amy. (2007). The Aggregate Effects of Health Insurance: Evidence from the Introduction of Medicare. Quarterly Journal of Economics. Volume 122, Issue 1, 84-99.

Follette, Glenn., Louise Sheiner.(2008).An Examination of Health Spending Growth in the United States: Past Trends and Future Prospects, Fiscal Sustainability. Analytical Developments and Emerging Policy Issues journal. Apr.

Gerdtham, G., Johannesson, M. (1997). New estimates of the demand for Health: results based on a categorical health measure and Swedish micro data. Department of economics. Stockholm School of Economics. Stockholm, Sweden. Working paper series in economics and finance. Volume12, NO 205, 107-139

Gregersen, FA. (2014). the impact of ageing on health care expenditures: a study of steepening. The European Journal of Health Economics.Volume 13, NO 15, 979-989

Getzen, TE. (2000). Forecasting health expenditures: short, medium, and long (long) term. J. Health Care Finance. Volume 26, No 3, 5672

Liran Einav, Amy Finkelstein, Paul Schrimpfy.(2015) .Implication for spending responses to health insurance contracts. Annual review of economics. Volume 8, No 5, 113-138.

Michael Grossman, M. (1972). On the Concept of Health Capital and the Demand for Health. The Journal of Political Economy. Volume 80, No. 2, 223-255.

Newhouse, Joseph. (1977). Medical-care expenditure: A cross-national survey.Journal of Human Resource Volume 12, No 1,115-25

Rasel, M. Ardalan, A. (2007). The future of ageing and its health care costs: a warning for health system.Salmand journal. Volume 2, No. 4, 114-139

Smith, Sheila, Joseph Newhouse and Mark Freeland. (2009). Income, Insurance and Technology: Why Does Health Spending Outpace Economic Growth. Health Affairs.

Sheiner, L. Perspective on health care spending growth. The future of U.S. health care spending conference.Engelberg center for health care reform at Brookings.

Wagstaff, A. (1986). The demand for health: some new empirical evidence. Journal of Health Economics. Volume .5, $195-233$. 